\title{
IMPACT OF GROUND WIRES ON THE SERIES IMPEDANCE, VOLTAGE AND CURRENT CONDITIONS OF OVERHEAD POWER LINES
}

\author{
A. MARGITOVÁ*, M. KANÁLIK ${ }^{* *}$, M. KOLCUN*** \\ Department of Electric Power Engineering Faculty of Electrical Engineering and Informatics, \\ Technical University of Košice, Letná 9, 04200 Košice, Slovak Republic, \\ tel. ${ }^{*}+421556023560,{ }^{* * *}+421556023555,{ }^{* * *}+421556023550$, \\ E-mail: *anastazia.margitova@tuke.sk, ${ }^{* *}$ martin.kanalik@tuke.sk, ${ }^{* * *}$ michal.kolcun@tuke.sk
}

\begin{abstract}
Ground wires are bare conductors which serve to protect the power line from the lightning strike. This article deals with the calculation of the series impedance of the $110 \mathrm{kV}$ overhead power line with one ground wire. The article examines the effect of the ground wire on the series impedance of the $110 \mathrm{kV}$ power line compared to the same power line without the ground wire. In the next part, the principle of elimination of the ground wire is described and the method of including the influence of the ground wire on the series impedance of phase conductors of the $110 \mathrm{kV}$ power line is also described. The conclusion deals with the calculation of voltage and current conditions of the $110 \mathrm{kV}$ power line modelled without the ground wire, with the ground wire and with elimination (reduction) of the ground wire (the ground wire is not modelled, but its effect is included in the series impedance of phase conductors) and then comparison of given models.
\end{abstract}

Keywords: series impedance of overhead power lines, reduction of ground wires

\section{INTRODUCTION}

The calculation of electrical parameters of overhead power lines is necessary for solving stationary and nonstationary phenomena occurring in electrical networks. In the case of power lines of different voltage levels, it is possible to consider the series impedance (resistance and inductance) and the shunt admittance (conductance and capacitance) of phase conductors. Aside from phase conductors, overhead power lines also include ground wires that have the protective function. Ground wires have their parameters (series impedance and shunt admittance). The series impedance of ground wires affects the overall series impedance of the power line as well as the operational characteristics of the power line.

Therefore, properties of ground wires must be taken into account when calculating the series impedance of overhead power lines. There are three basic concepts (Carson's, Rüdenberg's, and Deri's method [1]) for calculating the series impedance of overhead power lines. The purpose of presented methods for calculating the series impedance of overhead power lines is to create a simple way to determine both the self and the mutual parameters of conductors with required precision for a wide range of geometric arrangement, environment, materials, and so on. These methods differ from one to another according to configuration of conductors and properties of the ground. All theories assume that the biggest density of the alternating current in the ground is directly below the line and quickly drops to the sides as well as to the depth. All three theories consider that the earth has its own parameters (series impedance: ground resistance and inductance) [2], [3].

\section{CALCULATION OF THE SERIES IMPEDANCE OF OVERHEAD POWER LINES BY CARSON'S METHOD}

The Carson's theory was published in 1926 and is still a standard for calculating the series impedance of overhead power lines. Carson assumes that the earth is a uniform, flat, solid and infinite surface with the constant resistivity The method expresses the series impedance of power lines as an improper integral, which can be developed into infinite series. For practical purposes, it is sufficient to consider the final number of elements in the series [4].

The Carson's theory includes the influence of the earth on the series impedance of overhead power lines in the correction factors. The Carson's theory is based on the Fig. 1, which shows the model of two conductors (wire $\mathrm{k}$ and wire $\mathrm{m}$ ) and their mirror images (image $\mathrm{k}^{\prime}$ and image $\mathrm{m}^{\prime}$ ) with respect to the plane of the ground. For any number of conductors, the configuration of $m+n$ real conductors and one earth is replaced by $m+n$ real conductors and $m+n$ images of conductors ( $m$ is the number of phase conductors, $n$ is the number of ground wires).

Carson's method for calculating the series impedance of overhead power lines expresses relationships between conductors of one system (or power line), but also between several systems (or power lines). The result of the calculation is not a number, but a matrix of elements. The dimensions of the series impedance matrix (rows and columns) are identical to the number of conductors of the given system (or power line). In this matrix the self series impedance (self resistance and self inductance) of each conductor is placed on the matrix diagonal and relations between conductors (mutual series impedance: mutual resistance and mutual inductance) are expressed apart from the diagonal [2]. 


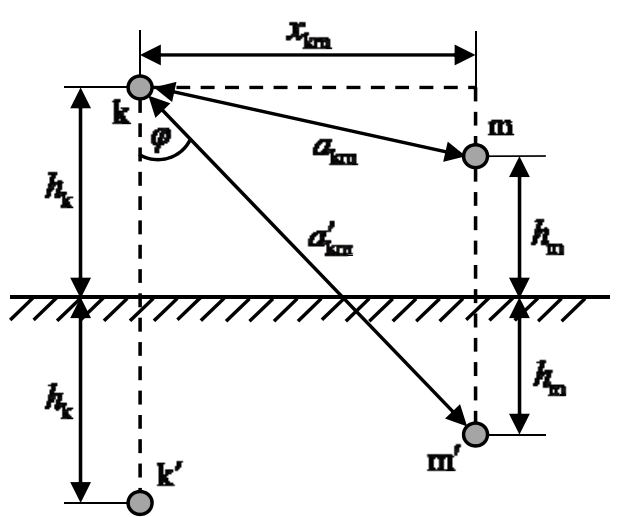

Fig. 1 Model of two conductors and their mirror images with respect to the plane of the earth

For the self series impedance $\dot{Z}_{\mathrm{kk}}$ of the conductor $\mathrm{k}$ and for the mutual series impedance $\dot{Z}_{\mathrm{km}}$ between the conductors $\mathrm{k}$ and $\mathrm{m}$ (as shown in Fig. 1):

$\dot{Z}_{\mathrm{kk}}=R_{\mathrm{kk}}+\mathrm{j} \omega L_{\mathrm{kk}} \quad\left(\Omega \mathrm{m}^{-1}\right)$,

$\dot{Z}_{\mathrm{km}}=R_{\mathrm{km}}+\mathrm{j} \omega L_{\mathrm{km}}\left(\Omega \mathrm{m}^{-1}\right)$,

$\dot{Z}_{\mathrm{km}}=\dot{Z}_{\mathrm{mk}}, L_{\mathrm{km}}=L_{\mathrm{mk}}, R_{\mathrm{km}}=R_{\mathrm{mk}}$,

where

$R_{\mathrm{kk}}$ is the self resistance of the conductor $\mathrm{k}\left(\Omega \mathrm{m}^{-1}\right)$,

$L_{\mathrm{kk}} \quad$ is the self inductance of the conductor $\mathrm{k}\left(\mathrm{Hm}^{-1}\right)$,

$R_{\mathrm{km}}$ is the mutual resistance between conductors $\mathrm{k}$ and $\mathrm{m}$ $\left(\Omega \mathrm{m}^{-1}\right)$,

$R_{\mathrm{mk}} \quad$ is the mutual resistance between conductors $\mathrm{m}$ and $\mathrm{k}\left(\Omega \mathrm{m}^{-1}\right)$,

$L_{\mathrm{km}} \quad$ is the mutual inductance between conductors $\mathrm{k}$ and $\mathrm{m}\left(\mathrm{Hm}^{-1}\right)$,

$L_{\mathrm{mk}} \quad$ is the mutual inductance between conductors $\mathrm{m}$ and $\mathrm{k}\left(\mathrm{Hm}^{-1}\right)$,

$\dot{Z}_{\mathrm{mk}} \quad$ is the mutual series impedance between conductors $\mathrm{m}$ and $\mathrm{k}\left(\Omega \mathrm{m}^{-1}\right)$,

$\omega \quad$ is the angular frequency $\left(\mathrm{s}^{-1}\right)$.

The self resistance $R_{\mathrm{kk}}$ and self inductance $L_{\mathrm{kk}}$ of the conductor k (Fig. 1) can be determined as [1]:

$R_{\mathrm{kk}}=R_{\mathrm{k}}+\Delta R_{\mathrm{kk}}=R_{\mathrm{k}}+4 \cdot 10^{-7} \omega P \quad\left(\Omega \mathrm{m}^{-1}\right)$,

$L_{\mathrm{kk}}=\frac{\mu_{0}}{2 \pi} \ln \left(\frac{2 h_{\mathrm{k}}}{\xi_{\mathrm{k}} r_{\mathrm{k}}}\right)+\Delta L_{\mathrm{kk}} \quad\left(\mathrm{Hm}^{-1}\right)$

$L_{\mathrm{kk}}=\frac{\mu_{0}}{2 \pi} \ln \left(\frac{2 h_{\mathrm{k}}}{\xi_{\mathrm{k}} r_{\mathrm{k}}}\right)+4 \cdot 10^{-7} Q\left(\mathrm{Hm}^{-1}\right)^{,}$

where

$R_{\mathrm{k}} \quad$ is the AC resistance of the conductor $k$ without considering the influence of the ground according to [3] (it may include the influence of temperature, skin effect, twisting ropes, and sag) $\left(\Omega \mathrm{m}^{-1}\right)$,

$\Delta R_{\mathrm{kk}} \quad$ is the Carson's correction factor for the conductor's $\mathrm{k}$ self resistance with respect to the ground $\left(\Omega \mathrm{m}^{-1}\right)$,

$\Delta L_{\mathrm{kk}} \quad$ is the Carson's correction factor for the conductor's $\mathrm{k}$ self inductance with respect to the ground $\left(\mathrm{Hm}^{-1}\right)$,
$P \quad$ is the factor determining the correction factor for the resistance $\left(\Omega \mathrm{m}^{-1}\right)$,

$Q \quad$ is the factor determining the correction factor for the inductance $\left(\mathrm{Hm}^{-1}\right)$,

$h_{\mathrm{k}} \quad$ is the height of the conductor k over the ground (m),

$\xi_{\mathrm{k}} \quad$ is the factor that represents the skin effect and magnetic properties of the conductor's $\mathrm{k}$ material $(-)$,

$r_{\mathrm{k}} \quad$ is the radius of the conductor $\mathrm{k}(\mathrm{m})$,

$\mu_{0} \quad$ is the vakuum permeability $\left(\mathrm{Hm}^{-1}\right)$, $\mu_{0}=4 \pi \cdot 10^{-7} \mathrm{Hm}^{-1}$.

For the mutual resistance $R_{\mathrm{km}}$ and inductance $L_{\mathrm{km}}$ between conductors $\mathrm{k}$ and $\mathrm{m}$, the following applies:

$R_{\mathrm{km}}=\Delta R_{\mathrm{km}}=4 \cdot 10^{-7} \omega P \quad\left(\Omega \mathrm{m}^{-1}\right)$,

$L_{\mathrm{km}}=\frac{\mu_{0}}{2 \pi} \ln \left(\frac{a_{\mathrm{km}}^{\prime}}{a_{\mathrm{km}}}\right)+\Delta L_{\mathrm{km}} \quad\left(\mathrm{Hm}^{-1}\right)$

$L_{\mathrm{km}}=\frac{\mu_{0}}{2 \pi} \ln \left(\frac{a_{\mathrm{km}}^{\prime}}{a_{\mathrm{km}}}\right)+4 \cdot 10^{-7} Q\left(\mathrm{Hm}^{-1}\right)^{,}$

where

$\Delta R_{\mathrm{km}} \quad$ is the Carson's correction factor for the mutual resistance between conductors $\mathrm{k}$ and $\mathrm{m}$ with respect to the ground $\left(\Omega \mathrm{m}^{-1}\right)$,

$\Delta L_{\mathrm{km}} \quad$ is the Carson's correction factor for the mutual inductance between conductors $\mathrm{k}$ and $\mathrm{m}$ with respect to the ground $\left(\mathrm{Hm}^{-1}\right)$,

$a_{\mathrm{km}}^{\prime} \quad$ is the distance between the conductor $\mathrm{k}$ and the image of the conductor $\mathrm{m}(\mathrm{m})$ according to Fig. 1,

$a_{\mathrm{km}} \quad$ is the distance between the conductor $\mathrm{k}$ and the conductor $\mathrm{m}(\mathrm{m})$ according to Fig. 1.

The factors $P$ and $Q$ which are used to determine correction factors for the resistance and inductance depend on the frequency, earth resistivity and configuration of conductors. Reference [3] contains equations for their calculation.

Many commercial software programs use a simplified Carson's method to calculate electrical parameters of power lines with the sufficient precision. The simplified version of Carson's equations considers only a few expressions in equations for calculating factors $P$ a $Q$. A simplified version of the Carson's equations is given in [1].

\section{IMPACT OF GROUND WIRES ON THE SERIES IMPEDANCE OF OVERHEAD POWER LINES}

Ground wires are bare conductors which serve to shield the line and intercept lighting stroke before it hits the current carrying conductors below. The ground wires are solidly connected to the ground at each tower in transmission and distribution system. AlFe conductors (for example AlFe 180/59) are used for ground wires, wires must not be used. The number of ground wires depends on the type of overhead power lines. Typically, one or two ground wires are used [5]. 
The existence of ground wires on the overhead power line extends the series impedance matrix by $n$ rows and $n$ columns ( $n$ is the number of ground wires). Simplification of the series impedance matrix is accomplished by eliminating (reduction) the $\mathrm{n}$ rows and $\mathrm{n}$ columns belonging to ground wires. The influence of ground wires is included in the matrix of the self and mutual series impedance of phase conductors (in the reduced impedance matrix). When deducting the reduced impedance matrix, it is assumed that voltage drops on ground wires are equal to zero.

For any overhead power line it is possible to express Ohm's law in the form [6]:

$$
\begin{aligned}
& {\left[\begin{array}{c}
{\left[\Delta \dot{U}_{\mathrm{c}}\right]} \\
{\left[\Delta \dot{U}_{\mathrm{g}}\right]=[0]}
\end{array}\right]=\left[\begin{array}{ll}
{\left[\dot{Z}_{\mathrm{cc}}\right]} & {\left[\dot{Z}_{\mathrm{cg}}\right]} \\
{\left[\dot{Z}_{\mathrm{gc}}\right]} & {\left[\dot{Z}_{\mathrm{gg}}\right]}
\end{array}\right]\left[\begin{array}{l}
{\left[\dot{I}_{\mathrm{c}}\right]} \\
{\left[\dot{I}_{\mathrm{g}}\right]}
\end{array}\right](\mathrm{V}),} \\
& {\left[\dot{Z}_{\mathrm{cc}}\right]=\left[R_{\mathrm{cc}}\right]+\mathrm{j} \omega\left[L_{\mathrm{cc}}\right] \quad\left(\Omega ; \Omega, \mathrm{s}^{-1}, \mathrm{H}\right),} \\
& {\left[\dot{Z}_{\mathrm{cg}}\right]=\left[R_{\mathrm{cg}}\right]+\mathrm{j} \omega\left[L_{\mathrm{cg}}\right] \quad\left(\Omega ; \Omega, \mathrm{s}^{-1}, \mathrm{H}\right),} \\
& {\left[\dot{Z}_{\mathrm{gc}}\right]=\left[R_{\mathrm{gc}}\right]+\mathrm{j} \omega\left[L_{\mathrm{gc}}\right] \quad\left(\Omega ; \Omega, \mathrm{s}^{-1}, \mathrm{H}\right),} \\
& {\left[\dot{Z}_{\mathrm{gg}}\right]=\left[R_{\mathrm{gg}}\right]+\mathrm{j} \omega\left[L_{\mathrm{gg}}\right] \quad\left(\Omega ; \Omega, \mathrm{s}^{-1}, \mathrm{H}\right),}
\end{aligned}
$$

where

$\left[\Delta \dot{U}_{\mathrm{c}}\right]$ is the column matrix of voltage drops in phase conductors of order $m \times 1(\mathrm{~V})$,

$\left[\Delta \dot{U}_{\mathrm{g}}\right]$ is the column matrix of voltage drops in ground wires of order $n \times 1(\mathrm{~V})$,

$\left[\dot{Z}_{\mathrm{cc}}\right] \quad$ is the square regular and symmetrical submatrix of order $m$ expressing the self and mutual series impedance of phase conductors $\left(\Omega \mathrm{m}^{-1}\right)$, it consists of the real component $\left[R_{\mathrm{cc}}\right]$ and the imaginary component $\omega\left[L_{\mathrm{cc}}\right]$,

$\left\lfloor\dot{Z}_{\mathrm{cg}}\right\rfloor \quad$ is the rectangular submatrix of order $m \times n$ expressing the mutual series impedance between phase conductors and ground wires $\left(\Omega \mathrm{m}^{-1}\right)$, it consists of the real component $\left[R_{\mathrm{cg}}\right]$ and the imaginary component $\omega\left[L_{\mathrm{cg}}\right]$,

$\left[\dot{Z}_{\mathrm{gc}}\right]$ is the rectangular submatrix of order $n \times m$ expressing the mutual series impedance between ground wires and phase conductors $\left(\Omega \mathrm{m}^{-1}\right)$, it consists of the real component $\left[R_{\mathrm{gc}}\right]$ and the imaginary component $\omega\left[L_{\mathrm{gc}}\right]$,

$\left\lfloor\dot{Z}_{\mathrm{gg}}\right\rfloor \quad$ is the square regular and symmetrical submatrix of order $n$ expressing the self and mutual series impedance of ground wires $\left(\Omega \mathrm{m}^{-1}\right)$, it consists of the real component $\left[R_{\mathrm{gg}}\right]$ and the imaginary component $\omega\left[L_{\mathrm{gg}}\right]$,

$\left[\dot{I}_{\mathrm{c}}\right] \quad$ is the column matrix of currents flowing in phase conductors of order $m \times 1(\mathrm{~A})$,

$\left[\dot{I}_{\mathrm{g}}\right]$ is the column matrix of currents flowing in ground wires of order $n \times 1(\mathrm{~A})$.

The reduced impedance matrix is obtained by expressing the matrix of currents flowing in ground wires $\left[\dot{I}_{\mathrm{g}}\right]$ from the second equation of the system (7), then by fitting it into the first equation of the system (7) and by modifying the system $(7)$ to the shape $\left[\Delta \dot{U}_{\mathrm{c}}\right]=\left[\dot{Z}_{\mathrm{red}}\right]\left[\dot{I}_{\mathrm{c}}\right]$ : $\left[\dot{Z}_{\mathrm{red}}\right]=\left[\dot{Z}_{\mathrm{cc}}\right]-\left[\dot{Z}_{\mathrm{cg}}\right]\left[\dot{Z}_{\mathrm{gg}}\right]^{-1}\left[\dot{Z}_{\mathrm{gc}}\right](\Omega)$, also for the reduced matrix of the resistance $\left[R_{\mathrm{red}}\right]$ and the inductance $\left[L_{\mathrm{red}}\right]$

$\left[R_{\mathrm{red}}\right]=\left[R_{\mathrm{cc}}\right]-\left[R_{\mathrm{cg}}\right]\left[R_{\mathrm{gg}}\right]^{-1}\left[R_{\mathrm{gc}}\right](\Omega)$,

$\left[L_{\mathrm{red}}\right]=\left[L_{\mathrm{cc}}\right]-\left[L_{\mathrm{cg}}\right]\left[L_{\mathrm{gg}}\right]^{-1}\left[L_{\mathrm{gc}}\right](\mathrm{H})$.

\section{CALCULATION OF THE SERIES IMPEDANCE OF THE SINGLE-CIRCUIT THREE-PHASE 110 KV OVERHEAD POWER LINE}

This chapter solves the calculation of the series impedance of single-circuit three-phase $110 \mathrm{kV}$ overhead power line shown in Fig. 2. The chapter compares the series impedance of the line (Fig. 2) determined without considering the existence of the ground wire with the incorporation of the ground wire into the calculation. Type of conductors of the single-circuit three-phase $110 \mathrm{kV}$ overhead power line and ground resistivity are described in Table 1.

The calculated parameters are given in ohms per kilometer (or millihenries per kilometer). Dimensions of the electric tower and configuration of phase conductors and ground wires in Fig. 2 are expressed in millimeters. In the case of the conductor's resistance, it is not considered the skin effect, operation temperature, rope twisting and even the sag.

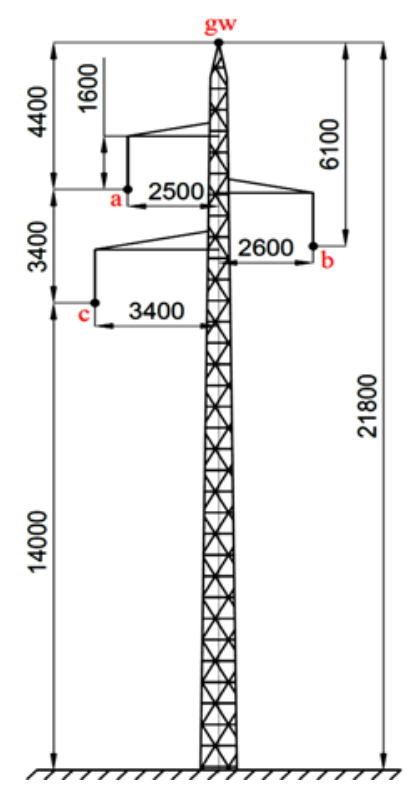

Fig. 2 Configuration of a single-circuit three-phase $110 \mathrm{kV}$ power line

Table 1 Type of conductors of the single-circuit three-phase $110 \mathrm{kV}$ overhead power line and the ground resistivity

\begin{tabular}{|c|c|}
\hline Type of the phase conductor & AlFe 240/39 \\
\hline Type of the ground wire & AlFe $180 / 59$ \\
\hline Resistivity of the ground & $150 \Omega \mathrm{m}$ \\
\hline
\end{tabular}

Applying the Carson's method to the model of the power line according to Fig. 2 (with consideration of the ground wire) for the self and mutual series impedance (inductance $\left[L_{\mathrm{gw}}\right]$ and resistance $\left[R_{\mathrm{gw}}\right]$ ) of the power line in the matrix form:

$\left[L_{\mathrm{gw}}\right]=\left[\begin{array}{ll}{\left[L_{\mathrm{cc}}\right]} & {\left[L_{\mathrm{cg}}\right]} \\ {\left[L_{\mathrm{gc}}\right]} & {\left[L_{\mathrm{gg}}\right]}\end{array}\right]$, 


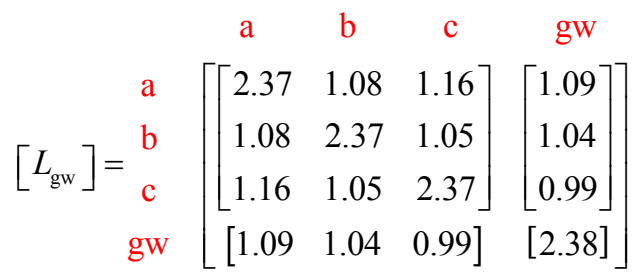

$$
\begin{aligned}
& {\left[R_{\mathrm{gw}}\right]=\left[\begin{array}{ll}
{\left[R_{\mathrm{cc}}\right]} & {\left[R_{\mathrm{cg}}\right]} \\
{\left[R_{\mathrm{gc}}\right]} & {\left[R_{\mathrm{gg}}\right]}
\end{array}\right],} \\
& \text { a } \quad b \quad c \quad \text { gw }
\end{aligned}
$$

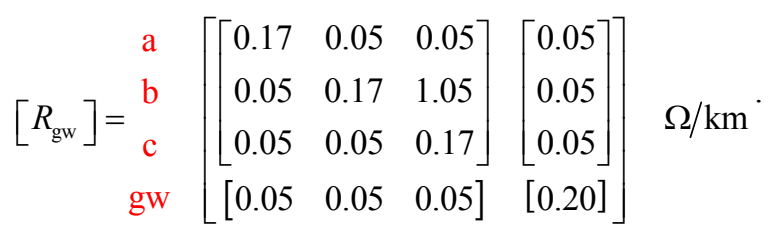$$
\mathrm{mH} / \mathrm{km}, \quad \dot{Z}_{\text {ab }}, \dot{Z}_{\text {ac }}, \dot{Z}_{\text {agw }}, \dot{Z}_{\text {ba }},
$$

$$
\begin{aligned}
& \dot{Z}_{\mathrm{aa}}, \dot{Z}_{\mathrm{bb}}, \dot{Z}_{\mathrm{cc}}, \dot{Z}_{\mathrm{gwgw}} \\
& \dot{Z}_{\mathrm{ab}}, \dot{Z}_{\mathrm{ac}}, \dot{Z}_{\mathrm{agw}}, \dot{Z}_{\mathrm{ba}}, \\
& \dot{Z}_{\mathrm{bc}}, \dot{Z}_{\mathrm{bgw}}, \dot{Z}_{\mathrm{ca}}, \dot{Z}_{\mathrm{cb}}, \\
& \dot{Z}_{\mathrm{cgw}}, \dot{Z}_{\mathrm{gwa}}, \dot{Z}_{\mathrm{gwb}}, \dot{Z}_{\mathrm{gwc}}
\end{aligned}
$$

After expressing the current flowing through the ground wire from the last equation of the system (17):

$\dot{I}_{\mathrm{gw}}=-\frac{1}{\dot{Z}_{\mathrm{gwgw}}}\left(\dot{Z}_{\mathrm{gwa}} \dot{I}_{\mathrm{a}}+\dot{Z}_{\mathrm{gwb}} \dot{I}_{\mathrm{b}}+\dot{Z}_{\mathrm{gwc}} \dot{I}_{\mathrm{c}}\right) \quad$ (A).

By substituting the current flowing through the ground wire (expressed by relation (18)) to the first, second and third equation of the system of equations (17), it is obtained [7]:

There are parameters (series impedance) of phase conductors and the ground wire found in matrices $\left[L_{\mathrm{gw}}\right]$ and $\left[R_{\mathrm{gw}}\right]$ with dimension $4 \times 4$ for the series impedance of the $110 \mathrm{kV}$ power line (inductance and resistance). Conductors and their respective rows and columns are marked in the matrices according to Fig. 2. The elements on the diagonal represent the self inductance and self resistance of each conductor. Out-of-diagonal values define mutual relationships (mutual inductance and mutual resistance) between conductors.

Matrices $\left[L_{\mathrm{no}-\mathrm{gw}}\right]$ and $\left[R_{\mathrm{no}-\mathrm{gw}}\right]$ for the inductance and resistance of the $110 \mathrm{kV}$ power line without consideration of the ground wire are equal to submatrices of the size $3 \times 3$ formed by matrices $\left[L_{\mathrm{gw}}\right]$ and $\left[R_{\mathrm{gw}}\right]$ considering the effect of the ground wire. After omitting the row and column for the ground wire (in matrices $\left[L_{\mathrm{gw}}\right]$ and $\left[R_{\mathrm{gw}}\right]$ ):

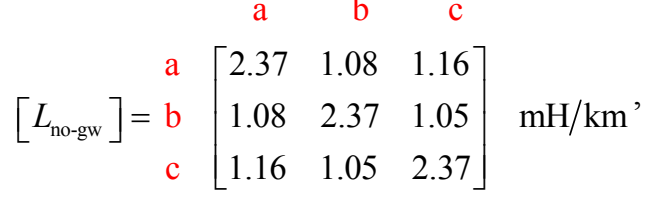

$$
\begin{aligned}
& {\left[R_{\text {no-gw }}\right]=\begin{array}{l}
\mathrm{a} \\
\mathrm{b}
\end{array}\left[\begin{array}{lll}
0.17 & 0.05 & 0.05 \\
0.05 & 0.17 & 1.05 \\
0.05 & 0.05 & 0.17
\end{array}\right] \Omega / \mathrm{km}}
\end{aligned}
$$

For the $110 \mathrm{kV}$ single-circuit overhead power line (according to Fig. 2) it is possible to define the Ohm law as a set of four equations [7] (indices belong to the conductors in Fig. 2):

$$
\left[\begin{array}{c}
\Delta \dot{U}_{\mathrm{a}} \\
\Delta \dot{U}_{\mathrm{b}} \\
\Delta \dot{U}_{\mathrm{c}} \\
\Delta \dot{U}_{\mathrm{gw}}=0
\end{array}\right]=\left[\begin{array}{cccc}
\dot{Z}_{\mathrm{aa}} & \dot{Z}_{\mathrm{ab}} & \dot{Z}_{\mathrm{ac}} & \dot{Z}_{\mathrm{agw}} \\
\dot{Z}_{\mathrm{ba}} & \dot{Z}_{\mathrm{bb}} & \dot{Z}_{\mathrm{bc}} & \dot{Z}_{\mathrm{bgw}} \\
\dot{Z}_{\mathrm{ca}} & \dot{Z}_{\mathrm{cb}} & \dot{Z}_{\mathrm{cc}} & \dot{Z}_{\mathrm{cgw}} \\
\dot{Z}_{\mathrm{gwa}} & \dot{Z}_{\mathrm{gwb}} & \dot{Z}_{\mathrm{gwc}} & \dot{Z}_{\mathrm{gwgw}}
\end{array}\right]\left[\begin{array}{c}
\dot{I}_{\mathrm{a}} \\
\dot{I}_{\mathrm{b}} \\
\dot{I}_{\mathrm{c}} \\
\dot{I}_{\mathrm{gw}}
\end{array}\right](\mathrm{V})
$$

where

$\Delta \dot{U}_{\mathrm{a}}, \Delta \dot{U}_{\mathrm{b}}, \Delta \dot{U}_{\mathrm{c}}$,

$\Delta \dot{U}_{\mathrm{gw}}$

$\dot{I}_{\mathrm{a}}, \dot{I}_{\mathrm{b}}, \dot{I}_{\mathrm{c}}, \dot{I}_{\mathrm{gw}}$

$$
\begin{aligned}
& {\left[\begin{array}{c}
\Delta \dot{U}_{\mathrm{a}} \\
\Delta \dot{U}_{\mathrm{b}} \\
\Delta \dot{U}_{\mathrm{c}}
\end{array}\right]=\left[\begin{array}{ccc}
\dot{Z}_{\mathrm{aa}} & \dot{Z}_{\mathrm{ab}} & \dot{Z}_{\mathrm{ac}} \\
\dot{Z}_{\mathrm{ba}} & \dot{Z}_{\mathrm{bb}} & \dot{Z}_{\mathrm{bc}} \\
\dot{Z}_{\mathrm{ca}} & \dot{Z}_{\mathrm{cb}} & \dot{Z}_{\mathrm{cc}}
\end{array}\right]\left[\begin{array}{c}
\dot{I}_{\mathrm{a}} \\
\dot{I}_{\mathrm{b}} \\
\dot{I}_{\mathrm{c}}
\end{array}\right]+\left[\begin{array}{l}
\dot{Z}_{\mathrm{agw}} \dot{I}_{\mathrm{gw}} \\
\dot{Z}_{\mathrm{bgw}} \dot{I}_{\mathrm{gw}} \\
\dot{Z}_{\mathrm{cgw}} \dot{I}_{\mathrm{gw}}
\end{array}\right]=} \\
& {\left[\dot{Z}_{\text {aa }}-\frac{\dot{Z}_{\text {agw }} \dot{Z}_{\text {gwa }}}{\dot{Z}_{\text {gwgw }}} \quad \dot{Z}_{\text {ab }}-\frac{\dot{Z}_{\text {agw }} \dot{Z}_{\text {gwb }}}{\dot{Z}_{\text {gwgw }}} \quad \dot{Z}_{\text {ac }}-\frac{\dot{Z}_{\text {agw }} \dot{Z}_{\text {gwc }}}{\dot{Z}_{\text {gwgw }}}\right]} \\
& \dot{Z}_{\mathrm{ba}}-\frac{\dot{Z}_{\mathrm{bgw}} \dot{Z}_{\mathrm{gwa}}}{\dot{Z}_{\mathrm{gwgw}}} \quad \dot{Z}_{\mathrm{bb}}-\frac{\dot{Z}_{\mathrm{bgw}} \dot{Z}_{\mathrm{gwb}}}{\dot{Z}_{\mathrm{gwgw}}} \quad \dot{Z}_{\mathrm{bc}}-\frac{\dot{Z}_{\mathrm{bgw}} \dot{Z}_{\mathrm{gwc}}}{\dot{Z}_{\mathrm{gwgw}}} \mid\left[\begin{array}{c}
\dot{I}_{\mathrm{a}} \\
\dot{I}_{\mathrm{b}} \\
\dot{I}_{\mathrm{c}}
\end{array}\right]= \\
& {\left[\dot{Z}_{\mathrm{ca}}-\frac{\dot{Z}_{\mathrm{cgw}} \dot{Z}_{\mathrm{gwa}}}{\dot{Z}_{\mathrm{gwgw}}} \quad \dot{Z}_{\mathrm{cb}}-\frac{\dot{Z}_{\mathrm{cgw}} \dot{Z}_{\mathrm{gwb}}}{\dot{Z}_{\mathrm{gwgw}}} \quad \dot{Z}_{\mathrm{cc}}-\frac{\dot{Z}_{\mathrm{cgw}} \dot{Z}_{\mathrm{gwc}}}{\dot{Z}_{\mathrm{gwgw}}}\right]^{\left[\dot{I}_{\mathrm{c}}\right.}} \\
& {\left[\begin{array}{ccc}
\dot{Z}_{\mathrm{aa}}+\Delta \dot{Z}_{\text {aa red }} & \dot{Z}_{\mathrm{ab}}+\Delta \dot{Z}_{\mathrm{ab} \mathrm{red}} & \dot{Z}_{\mathrm{ac}}+\Delta \dot{Z}_{\mathrm{ac} \text { red }} \\
\dot{Z}_{\mathrm{ba}}+\Delta \dot{Z}_{\mathrm{ba} \text { red }} & \dot{Z}_{\mathrm{bb}}+\Delta \dot{Z}_{\mathrm{bbred}} & \dot{Z}_{\mathrm{bc}}+\Delta \dot{Z}_{\mathrm{bc} \mathrm{red}} \\
\dot{Z}_{\mathrm{ca}}+\Delta \dot{Z}_{\mathrm{ca} \text { red }} & \dot{Z}_{\mathrm{cb}}+\Delta \dot{Z}_{\mathrm{cb} \text { red }} & \dot{Z}_{\mathrm{cc}}+\Delta \dot{Z}_{\mathrm{cc} \mathrm{red}}
\end{array}\right]\left[\begin{array}{c}
\dot{I}_{\mathrm{a}} \\
\dot{I}_{\mathrm{b}} \\
\dot{I}_{\mathrm{c}}
\end{array}\right]=} \\
& {\left[\begin{array}{lll}
\dot{Z}_{\text {aa red }} & \dot{Z}_{\text {ab red }} & \dot{Z}_{\text {ac red }} \\
\dot{Z}_{\text {ba red }} & \dot{Z}_{\text {bb red }} & \dot{Z}_{\text {bc red }} \\
\dot{Z}_{\text {ca red }} & \dot{Z}_{\text {cb red }} & \dot{Z}_{\text {cc red }}
\end{array}\right]\left[\begin{array}{c}
\dot{I}_{\mathrm{a}} \\
\dot{I}_{\mathrm{b}} \\
\dot{I}_{\mathrm{c}}
\end{array}\right]}
\end{aligned}
$$

The elimination of the ground wire of the single-circuit $110 \mathrm{kV}$ line with one ground wire according to relations (17), (18), (19) can only be applied if simplification is considered: zero voltage drop on the ground wire. The self series impedance of the ground wire and the mutual series impedance between phase conductors and the ground wire are included in the series impedance matrix of phase conductors in the form of correction factors $\Delta \dot{Z}_{\text {red }}$, that reduce the total resistivity and inductance (series impedance) of the power line.

After the ground wire elimination (Fig. 2), the series impedance matrix of phase conductors is as follows:

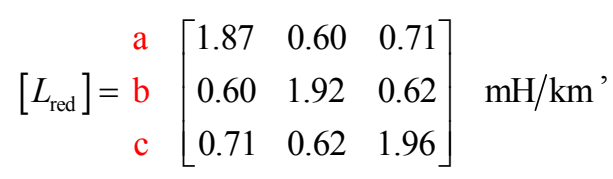

$$
\left[R_{\text {red }}\right]=\begin{array}{ccc}
\mathrm{a} & \mathrm{b} & \mathrm{c} \\
\mathrm{a} & \mathrm{b} \\
\mathrm{c} & {\left[\begin{array}{ccc}
0.15 & 0.04 & 0.04 \\
0.04 & 0.15 & 0.04 \\
0.04 & 0.04 & 0.15
\end{array}\right] \Omega / \mathrm{km} .}
\end{array}
$$

are voltage drops in phase conductors and the ground wire (V),

are currents flowing in phase conductors and the ground wire (A), 
There is a graphical comparison of the series impedance (self and mutual inductance and resistance) of the $110 \mathrm{kV}$ power line calculated by the Carson's method with consideration of the ground wire and without including the influence of the ground wire, shown in Fig. 3 to Fig. 6.

If the ground wire is not considered, values for the self inductance (Fig. 3) are constant. However, taking into account the influence of the ground wire, its existence reduces the self inductance of each phase conductor. Fig. 3 also shows that the self inductances of phase conductors a, $\mathrm{b}$ and $\mathrm{c}$ are not constant (in the case of the ground wire considering). The smaller distance of the phase conductor from the ground wire, the less its self inductance (compared to the self inductance without considering the ground wire). The existence of the ground wire also reduces the inductance between the phase conductors $\mathrm{a}-\mathrm{b}$ and $\mathrm{a}-\mathrm{c}$ (Fig. 4). The larger the distance between two conductors, the smaller inductive coupling between them (mutual inductance).

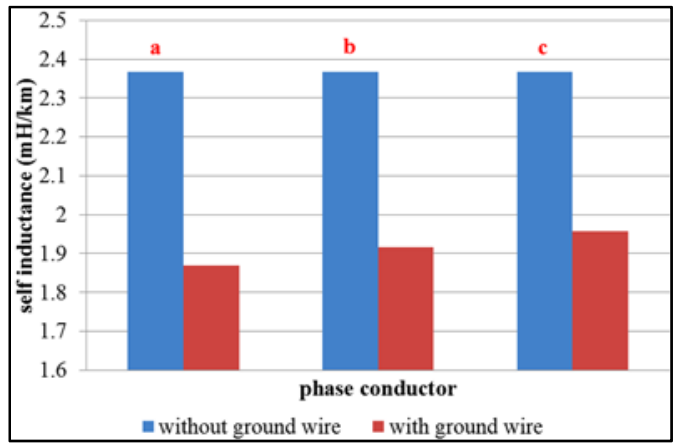

Fig. 3 Comparison of the self inductance of the single-circuit $110 \mathrm{kV}$ power line with and without consideration of the influence of the ground wire

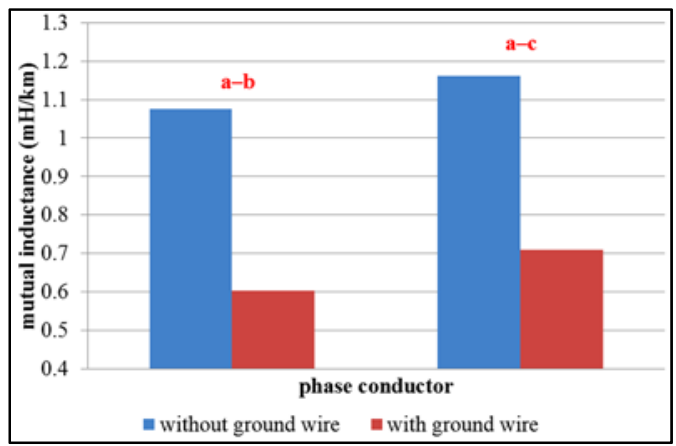

Fig. 4 Comparison of the mutual inductance of the singlecircuit $110 \mathrm{kV}$ power line with and without consideration of the influence of the ground wire

In the case of no grounding rope consideration both self-resistance and mutual resistance have the same values. The existence of the ground wire reduces these values by the same measure (Fig. 5 and Fig. 6). The self resistance of phase conductors includes, in addition to the resistance of phase conductors themselves, also the correction resistance $\Delta R_{\mathrm{aa}}, \Delta R_{\mathrm{bb}}$ and $\Delta R_{\mathrm{cc}}$ (Carson's correction factors for the self resistance of phase conductors a, b, c). The correction resistance represents active losses caused by non-zero ground impedance. The mutual resistance between phase conductors $\mathrm{a}-\mathrm{b}$ and $\mathrm{a}-\mathrm{c}$ is characterized by Carson's correction factors $\Delta R_{\mathrm{ab}}$ and $\Delta R_{\mathrm{ac}}$ which represent a phase shift that is included in the induced voltage due to the existing of series impedance of the ground [1], [3].

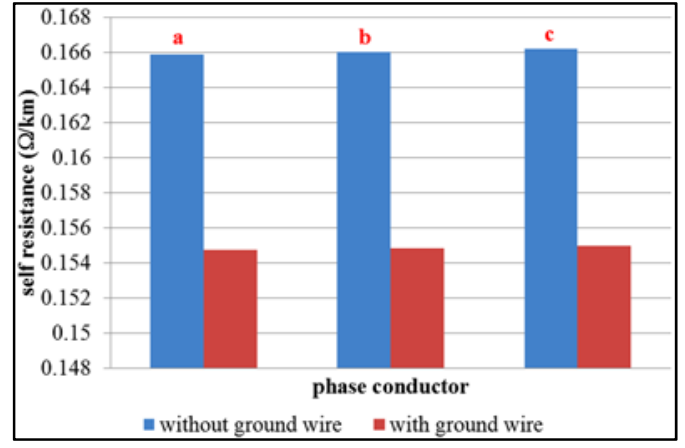

Fig. 5 Comparison of the self resistance of the single-circuit $110 \mathrm{kV}$ power line with and without consideration of the influence of the ground wire

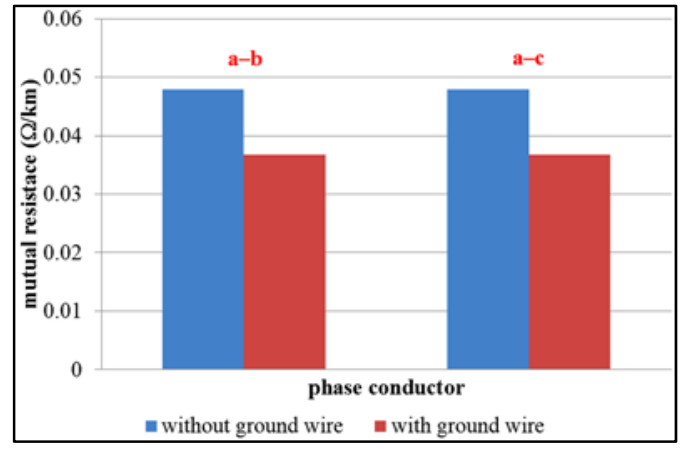

Fig. 6 Comparison of the mutual resistance of the single-circuit $110 \mathrm{kV}$ power line with and without consideration of the influence of the ground wire

\section{CALCULATION OF VOLTAGE AND CURRENT CONDITIONS OF THE SINGLE-CIRCUIT THREE-PHASE 110 KV OVERHEAD POWER LINE}

This chapter deals with the calculation of voltage and current conditions of the $110 \mathrm{kV}$ power line with the configuration of conductors according to Fig. 2, with parameters of conductors and the ground listed in Table 1. Two steady states were studied:

- normal operating conditions (at the end of the line the load $\dot{Z}_{\text {load }}=132.79 \mathrm{e}^{\mathrm{j} 18.2^{\circ}} \Omega$ is connected in each phase, the internal resistance $\dot{Z}_{\mathrm{i}}=R_{\mathrm{i}}=10^{-3} \Omega$ of sources is considered) - state I,

- single-phase short-circuit in the phase a (in phases b, c the load $\dot{Z}_{\text {load }}=132.79 \mathrm{e}^{\mathrm{j} 18.2^{\circ}} \Omega$ is connected, in the phase a $\dot{Z}_{\text {load }}=0 \Omega$, the short-circuit reactance $\dot{Z}_{\mathrm{i}}=\mathrm{j} X_{\mathrm{i}}=\mathrm{j} 3.04 \Omega$ of sources is considered) - state II.

The length of the power line was considered $19.5 \mathrm{~km}$. The spacing between towers was 300 meters (the power line was divided into 65 sections), the ground wire was grounded through each tower by the resistance $R_{\mathrm{g}}=15 \Omega$. An effective value of the phase voltage of sources was considered as $68.13 \mathrm{kV}$ (118 kV line to line voltage).

If the existence of the ground wire is not considered and symmetric three-phase current with an RMS value of $500 \mathrm{~A}$ flows through phase conductors, voltage drops on one section (index sec) of the power line $(300 \mathrm{~m})$ will have a size: 


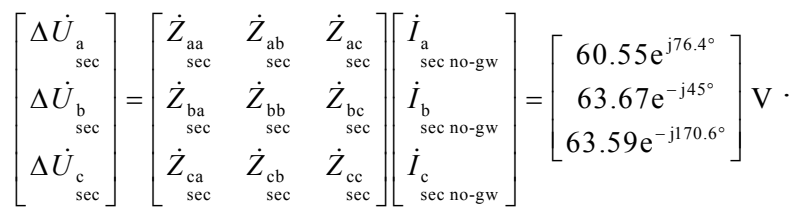

Although phases a, b, c of the $110 \mathrm{kV}$ power line are loaded with a symmetrical current, voltage drops in phases $\mathrm{a}, \mathrm{b}, \mathrm{c}$ differ in the size and the phase shift between voltage drops is not $120^{\circ}$. This voltage asymmetry is caused by different interconnections between conductors (the mutual series impedance between phases $\mathrm{a}-\mathrm{b}$ does not equal the mutual series impedance between phases $a-c, b-c)$. In the case of other types of power lines with different configuration and parameters of conductors, the self series impedance of phase conductors may also differ. The reason of the asymmetry of the self and mutual series impedance of phase conductors is different distances between conductors and between conductors and the ground.

If the same voltage drop in phase conductors and the zero voltage drop in the ground wire are considered for the four-conductor system (with considering the ground wire), for currents flowing through phase conductors and the ground wire, the following applies:

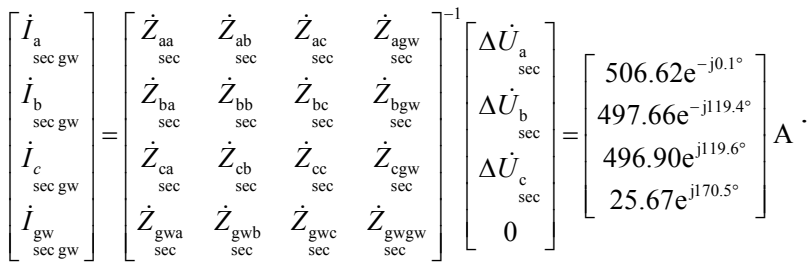

The same currents flowing through phase conductors a, $\mathrm{b}, \mathrm{c}$ are obtained even after the ground wire is reduced, its effect is included in the phase conductor impedance matrix. The same voltage drop in phase conductors is considered as in previous cases (four-conductor system and threeconductor system without the ground wire).

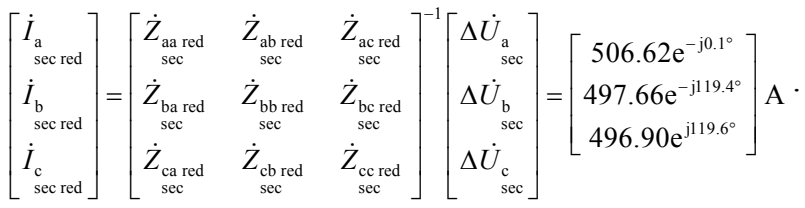

By comparing the above results for one section of the $110 \mathrm{kV}$ power line, the existence of the ground wire affects voltage and current conditions of the power line. Assuming equal voltage drops on phase conductors and zero voltage drop in the ground wire, the currents flowing through phase conductors without considering the ground wire differ from the currents in the same line with the ground wire both in the size and phase.

The node voltage method was used to determine currents flowing through phase conductors and the ground wire of the $110 \mathrm{kV}$ power line described above, as well as the voltage at nodes defined along the power line from the beginning to the end. The $110 \mathrm{kV}$ power line was modelled in three ways:

- without the ground wire (three-conductor system model I),

- with the ground wire (four-conductor system - model II) and
- with the reduced ground wire (three-conductor system with the inclusion of the series impedance of the ground wire to the series impedance of phase conductors model III).

Equivalent circuits of given models (model I, model II, model III) are shown in Fig. 7, Fig. 8 and Fig. 9. In these equivalent circuits the self series impedance of conductors are shown. The mutual series impedance between conductors is indicated by the curve with arrows. The process of creating the topology of given models and the mathematical solution of voltage and current conditions of the $110 \mathrm{kV}$ power line by the node voltage method is described in [3].

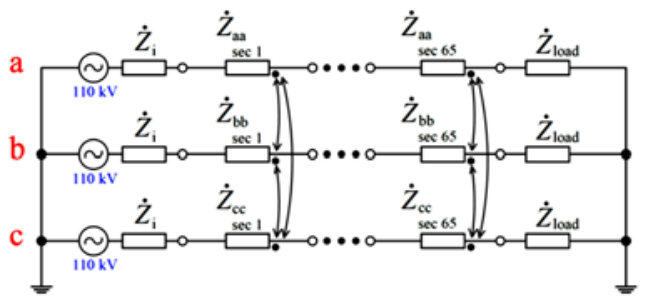

Fig. 7 Equivalent electromagnetic circuit of the single-circuit three-phase $110 \mathrm{kV}$ power line without the ground wire (model I)

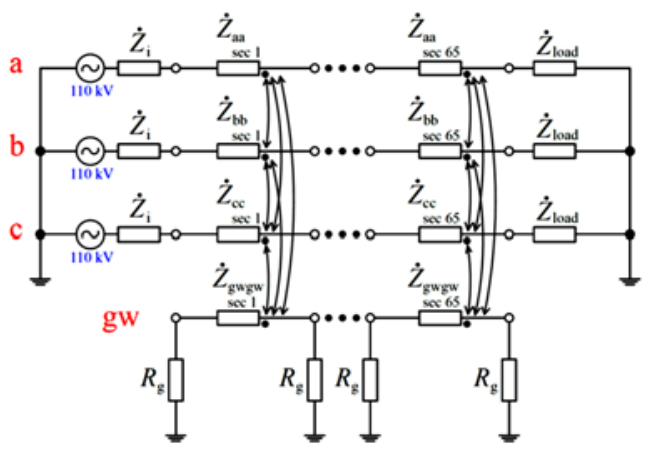

Fig. 8 Equivalent electromagnetic circuit of the single-circuit three-phase $110 \mathrm{kV}$ power line with the ground wire (model II)

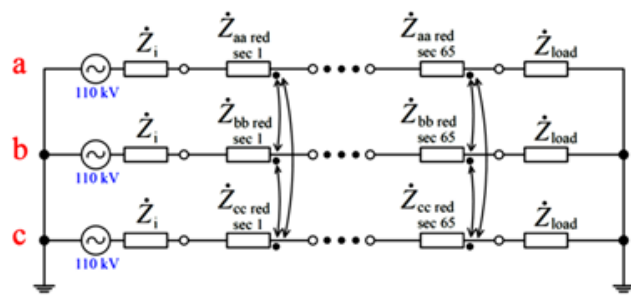

Fig. 9 Equivalent electromagnetic circuit of the single-circuit three-phase $110 \mathrm{kV}$ power line with the reduced ground wire (model III)

Currents flowing in phases a, b, c obtained for model I, II and III of the $110 \mathrm{kV}$ power line and steady states (state I and II) are shown in Table 2 and Table 3.

In the case of normal operating conditions, results obtained with all three models are practically equivalent. In the case of results for state II - a single-phase short-circuit in the phase a, phase currents determined by three models of the $110 \mathrm{kV}$ power line differ considerably from one another. The reason for this is the fact, that the increase of the current asymmetry (caused by a single-phase shortcircuit: asymmetric load) increases the influence of the ground wire on the redistribution of the current flow in conductors. In the case of model I (model without the 
ground wire), the short-circuit current flows only through the ground; in the case of model II, the existence of the ground wire reduces the impedance of the loop conductor - ground, which is accompanied by increasing the RMS value of the short-circuit current. The flow of the shortcircuit current through the ground wire also affects RMS values of currents flowing in healthy phases (because of increasing of asymmetry). In the case of model III, it can be seen that the influence of the ground wire on the value of the short-circuit current as well as the overall current asymmetry is even more significant than in the case of model II. The reason is the fact, that when the ground wire is eliminated (model III), it is assumed that the voltage drop on the ground wire is zero, but this is not true.

Table 2 Current flowing in phase conductors of the singlecircuit three-phase $110 \mathrm{kV}$ power line under normal operating conditions (state I)

\begin{tabular}{c|l|l|l}
\hline State I & \multicolumn{3}{|c}{ Model of the 110 kV power line } \\
\hline $\begin{array}{c}\text { Current } \\
\text { (A) }\end{array}$ & \multicolumn{1}{|c}{ Model I } & \multicolumn{1}{|c}{ Model II } & \multicolumn{1}{c}{ Model III } \\
\hline Phase a & $496.8 \mathrm{e}^{-\mathrm{j} 21^{\circ}}$ & $497.2 \mathrm{e}^{-\mathrm{j} 20.9^{\circ}}$ & $497.4 \mathrm{e}^{-\mathrm{j} 20.9^{\circ}}$ \\
Phase b & $495.5 \mathrm{e}^{-\mathrm{j} 141.1^{\circ}}$ & $494.8 \mathrm{e}^{-\mathrm{j} 141.1^{\circ}}$ & $494.7 \mathrm{e}^{-\mathrm{j} 141.1^{\circ}}$ \\
Phase c & $493.3 \mathrm{e}^{\mathrm{j} 99.1^{\circ}}$ & $493.5 \mathrm{e}^{\mathrm{j} 99.1^{\circ}}$ & $493.4 \mathrm{e}^{\mathrm{j} 99.1^{\circ}}$ \\
\hline
\end{tabular}

Table 3 Current flowing in phase conductors of the singlecircuit three-phase $110 \mathrm{kV}$ power line during a single-phase short-circuit in the phase a (state II)

\begin{tabular}{l|c|c|c}
\hline $\begin{array}{c}\text { State II } \\
\begin{array}{c}\text { Current } \\
\text { (A) }\end{array}\end{array}$ & Model I & Model II & Model III \\
\hline Phase a & $4011.7 \mathrm{e}^{-\mathrm{j} 75.6^{\circ}}$ & $4566.5 \mathrm{e}^{-\mathrm{j} 74.2^{\circ}}$ & $4721.4 \mathrm{e}^{-\mathrm{j} 75.6^{\circ}}$ \\
Phase b & $585.9 \mathrm{e}^{-\mathrm{j} 157.5^{\circ}}$ & $550.5 \mathrm{e}^{-\mathrm{j} 155.2^{\circ}}$ & $548.5 \mathrm{e}^{-\mathrm{j} 153.7^{\circ}}$ \\
Phase c & $610.9 \mathrm{e}^{\mathrm{j} 112.5^{\circ}}$ & $591.6 \mathrm{e}^{\mathrm{j} 109.5^{\circ}}$ & $579.4 \mathrm{e}^{\mathrm{j} 109.3^{\circ}}$ \\
\hline
\end{tabular}

Fig. 10 shows the RMS phase voltage in the phase a in sections of the $110 \mathrm{kV}$ power line determined by models I, II and III under normal operating conditions (state I). As in the case of phase currents obtained for the state I, voltages for models I, II, III are slightly different. The voltage drops from the beginning of the power line to its end, the voltage drop is caused by the series impedance of the power line.

RMS values of voltages and currents in sections of the ground wire of the $110 \mathrm{kV}$ power line for state I and II (determined using model II) are shown in Fig. 11 and Fig. 12.

In state I there are voltage and current conditions with very little asymmetry, a relatively low voltage (in the range of $0.17 \mathrm{~V}$ to $33.75 \mathrm{~V}$ ) is induced in the ground wire and the current flowing in the ground wire is in the range of $2.25 \mathrm{~A}$ to 20.9 A. Since every 300 meters the ground wire is grounded, the RMS value of the current flowing along the ground wire is not constant (as it is in the case of phase conductors), but the lowest values of the current are at the ends of the ground wire and the highest value is in the center of the ground wire. In the case of the RMS voltage along the ground wire, the situation is the opposite, so the voltage reaches the largest value at the ends of the ground wire and the smallest values in the center of the ground wire. This is associated with the fact that the reactive power flows from both ends of the ground wire to the center of the ground wire, the active power flows in the opposite direction, from the center of the ground wire to two ends of the ground wire.

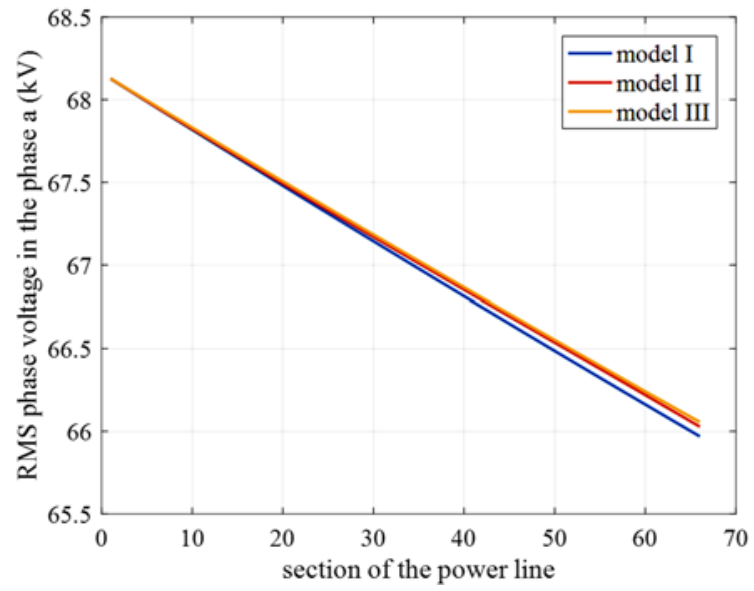

Fig. 10 RMS phase voltage in the phase a in sections of the single-circuit three-phase $110 \mathrm{kV}$ power line under normal operating conditions (state I)
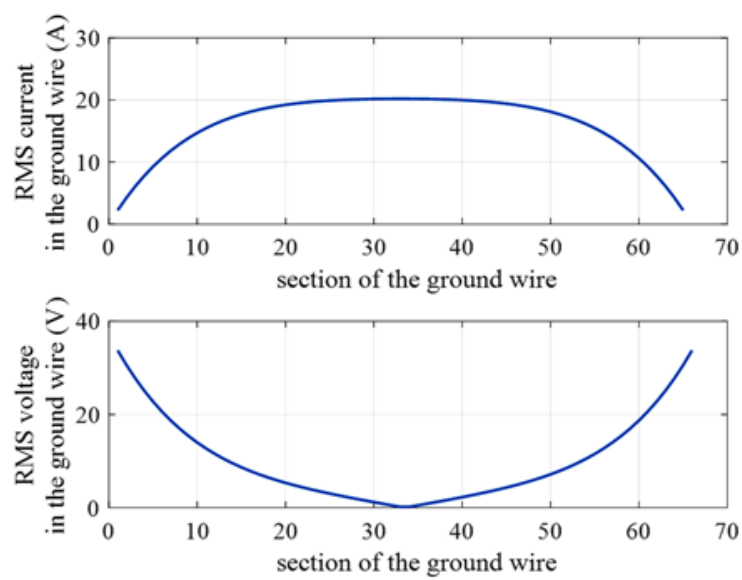

Fig. 11 RMS current and voltage in sections of the ground wire of the single-circuit three-phase $110 \mathrm{kV}$ power line under normal operating conditions (state I)

In the case of model II (single-phase short-circuit), the voltage and the current in each section of the ground wire have the same characteristics as for model I (normal operating conditions). However, the RMS value of the current flowing through the ground wire compared to the state I increased in this case approximately 100 times (at the ends and in the middle of the ground wire), and consequently the RMS value of the voltage in sections of the ground wire increased approximately 100 times.
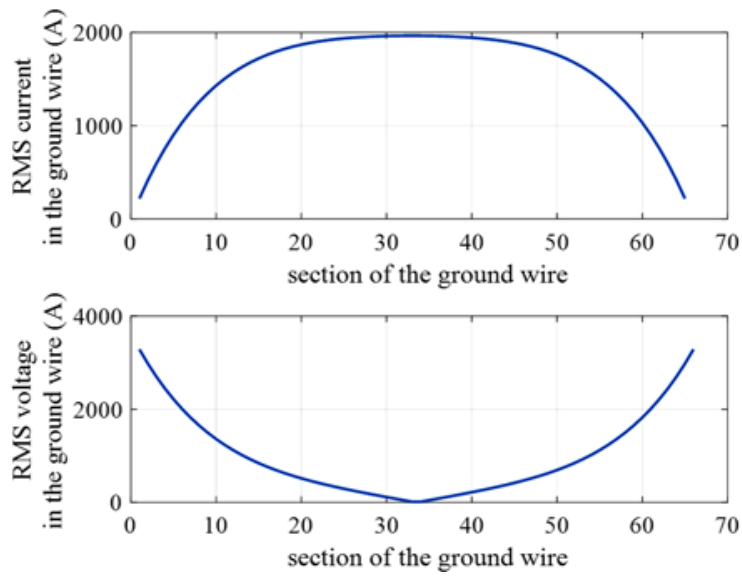

Fig. 12 RMS current and voltage in sections of the ground wire of the single-circuit three-phase $110 \mathrm{kV}$ power line during a single-phase short-circuit in the phase a (state II) 


\section{CONCLUSION}

In the case of calculations of electrical quantities, whether in a steady state or in the case of transient phenomena, the mathematical modelling of overhead power lines often uses the series impedance and shunt admittance values, which generally depend only on the cross-section of the phase conductor. With today's wellknown and proven approaches, it is possible to create multiple mathematical models of overhead power lines, each of which is suitable for a different purpose.

Chapter 2 of this article describes the Carson's method of calculating the self and mutual series impedance of conductors of overhead power line, which also depends on the number of conductors and distances between conductors, and distances between conductors and the ground. On the basis of calculated electric parameters (series impedance) of conductors, for example, in the case of the single-circuit three-phase $110 \mathrm{kV}$ power line, three different models can be created: three-conductor system without the ground wire, four-conductor system with the ground wire and three-conductor system with the eliminated ground wire. For each of these models, different values of self and mutual resistance and inductance of the power line (of conductors) can be found.

There are voltage and current conditions of given three models of the $110 \mathrm{kV}$ power line solved in the chapter 5 . From above results, the ground wire significantly influences voltages and currents of the $110 \mathrm{kV}$ power line in the case of increased asymmetry on the source side (voltage unbalance) or on the load side. Even the parameters (series impedance) of the power line are not symmetrical, but it is a small asymmetry caused by different distances between conductors and between conductors and the ground.

It follows that in the modelling of unbalanced disturbances, respectively of unsymmetrical operating states it is necessary to include the ground wire into the calculation. On the other hand, in the case of voltage and current symmetry, the effect of the ground wire is minimal. It is also necessary to take into account the fact, that when the ground wire is eliminated in order to simplify calculations, a voltage drop on the ground wire is considered equal to zero, which represents an inaccuracy in the calculations.

\section{ACKNOWLEDGMENTS}

This work was supported by the Ministry of Education, Science, Research and Sport of the Slovak Republic and the Slovak Academy of Sciences under the contract No. VEGA 1/0372/18.

\section{REFERENCES}

[1] MARGitovÁ, A. - KOLCUN, M. - KANÁLIK, M. - KOSTEREC, M.: Porovnanie metód na výpočet pozdížnej impedancie vedení, ELEKTROENERGETIKA, Vol. 11, No. 1, pp. 341$351,2018$.

[2] REISS, L. - MALÝ, K. - PAVLÍČEK, Z. NĚMĚČEK, F.: Teoretická elektroenergetika I, $2^{\text {nd }}$ ed. Bratislava: Alfa, 1997.
[3] MARGITOVÁ, A.: Výpočet elektrických parametrov silových vedení, Bachelor thesis. Technická univerzita v Košiciach, 2015.

[4] CARSON, J. R.: Wave Propagation in Overhead Wires with Ground Return, Bell System Technical Journal, vol. 5, pp. 539-554, 1926.

[5] HARANGOZO, J.: Vonkajšie vedenia, Prešov: SPŠE, 2008.

[6] BEATY, H. W.: Handbook of Electric Power Calculations, $3^{\text {rd }}$ ed. McGraw-Hill, 2001.

[7] HASE, Y.: Handbook of power systems engineering, John Wiley \& Sons, 2007.

Received October 12, 2018, accepted March 06, 2019

\section{BIOGRAPHIES}

Anastázia Margitová was born in 1993 in Prešov. She is a PhD. student at the Department of Electric Power Engineering on the Faculty of Electrical Engineering and Informatics at Technical University in Košice. She received a master degree in electric power engineering in 2017. Her scientific research is focusing on a power system control and computer application in electric power engineering.

Martin Kanálik was born in Prešov, Slovakia in 1981. He received the the MSc. degree from the Technical University of Košice, Slovakia in 2005 and the PhD. degree from the Technical University of Košice in 2008. He is an assistant professor at the Department of Electric Power Engineering at Technical University in Košice, since 2013. His major fields of interests are the computer modelling of power systems, power quality and fault analysis in power systems.

Michal Kolcun was born in 1954 in Ruska Vola nad Popradom. In 1979 he graduated at the Faculty of Electric Power Engineering of the Moscow Power Engineering Institute. In 1989 he defended his $\mathrm{PhD}$ on the same institute in Moscow. In 1993 he habilitated to associated professor at the department of Electric Power Engineering on the Faculty of Electrical Engineering and Informatics at Technical University in Košice. In 2000 he inaugurate to professor, in the field of Power Engineering and Energetics, at the Faculty of Electrical Engineering and Informatics at Technical University in Košice. Since 2006 he is honorary professor at ÓBUDA University in Budapest, Hungary. Since June, 2012 he is Doctor Honoris Causa from Politechnika Czestochowa, Poland. Since 1979 he is working at the Department of Electric Power Engineering on the Faculty of Electrical Engineering and Informatics at Technical University in Košice. His scientific research is focusing on a power system control and computer application in electric power engineering. In addition, he also gives lectures in multiple foreign universities in Moscow, Sankt Peterburg, Czestochowa, Zelona Gorza, Budapest, Riga, Tallinn, Varna, Prague, Ostrava and Barcelona. 